\title{
SARS-CoV-2 will continue to circulate in the human population: an opinion from the point of view of the virus-host relationship
}

\author{
Volodymyr V. Oberemok ${ }^{1} \cdot$ Kateryna V. Laikova $^{1} \cdot$ Kseniya A. Yurchenko ${ }^{1} \cdot$ Irina I. Fomochkina ${ }^{1}$. \\ Anatolii V. Kubyshkin ${ }^{1}$ [D
}

Received: 6 April 2020 / Revised: 17 April 2020 / Accepted: 20 April 2020 / Published online: 30 April 2020

(c) Springer Nature Switzerland AG 2020

\begin{abstract}
At the population level, the virus-host relationship is not set up to end with the complete elimination of either or both. Pathogen-resistant individuals will always remain in the host population. In turn, the virus can never completely eliminate the host population, because evolutionarily such an event is a dead end for the virus as an obligate intracellular parasite. A certain existential balance exists in the virus-host relationship. Against this backdrop, viral epidemics and pandemics only become manifest and egregious to human beings when tens and hundreds of thousands of people die and the question emerges what caused the high mortality peaks on the death chart. The answer seems clear; the emerging strain of the virus is new to the host population, and new mutations of the virus and natural selection will lead to a survival of only genetically resistant individuals in a host population. The dangers inherent to a novel virus are due to new features generally inthe molecular structure of proteins, which enable the virus to infect the cells of the host organism more intensively, dramatically challenging host immunity, and thus be transmitted more readily in the host population. In this article, we will concentrate on the facts currently available about severe acute respiratory syndrome coronavirus 2 (SARS-CoV-2), which has caused COVID-19 (coronavirus disease 2019) pandemic and try to predict its development and consequences based on the virushost relationship. In fact, only two scenarios will occur simultaneously in the very near future: people who are genetically resistant to the virus will get sick, recover, and develop immunity, while people who are sensitive to the virus will need drugs and vaccines, which will have to be researched and developed if they are to recover. If the pandemic does not stop, in a few decades it is anticipated that SARS-CoV-2 will become as safe as the four non-severe acute respiratory syndrome human coronaviruses (HCoV-NL63, HCoV-HKU1, HCoV-OC43, and HCoV-229E) currently circulating but causing low mortality in the human population.
\end{abstract}

Keywords SARS-CoV-2 $\cdot$ Virus-host relationship system $\cdot$ Pandemic

Genomic alignments suggest that the COVID-19 virus (SARS-CoV-2) from the genus Betacoronavirus may be the result of recombination of genetic material from two different viruses, one similar to the Chinese horseshoe bat virus [1] and the other closer to the pangolin virus (two divergent viruses could have infected the same organism simultaneously). To date, aside from bat coronavirus RaTG13 (96.2\% similarity), the Pangolin-CoV (91.02\% similarity) is the

Responsible Editor: John Di Battista.

Anatolii V. Kubyshkin

kubyshkin_av@mail.ru

1 V.I. Vernadsky Crimean Federal University, Simferopol, Russia coronavirus most closely related to SARS-CoV-2 [2]. Even though the exact origin of the virus remains unclear, it is possible to infect a Chinese horseshoe bat or a pangolin with the SARS-CoV-2 and evaluate the success of the infection to determine the origin of the new virus responsible for the pandemic: did it come from animals or from a laboratory? While the absence of disease symptoms in these animals may be due to the effectiveness of their immune systems, the intensity of viral proliferation can be easily detected using the real-time PCR technique. However, the genie has already escaped from the bottle, and now we need to deal with the result, not the cause. Moreover, a 'hand-made' virus is likely to be effective against both animals and humans. Investigations suggest that SARS-CoV-2 may bind human ACE2 (angiotensin-converting enzyme 2) receptor with high 
affinity but computational analyses predict that the interaction is not ideal and that the RBD (receptor-binding domain) of the spike protein of SARS-CoV-2 is optimized for binding to human ACE2 receptor with an efficient solution different from those previously predicted [3, 4]. This evidence is strongly arguing against culture-based scenarios. Thus, the high-affinity binding of the SARS-CoV-2 spike protein to human ACE2 receptor is most likely the result of natural selection on a human or human-like ACE2 receptor that permits another optimal binding solution to arise. However, more scientific facts are needed to answer the question about the origin of the virus. Obtaining related viral sequences from animal sources would be the most definitive way of revealing viral origins [1]. The possibility of the existence of a potential intermediate host of SARS-CoV-2, a missing link between a bat and human or a pangolin and human can also shed light on the current pandemic. To date, however, there is no credible evidence to support the claim that SARS-CoV-2 originated from a laboratory-engineered coronavirus [5].

In early December 2019, the first cases of pneumonia of unknown origin were identified in Wuhan, the capital city of Hubei province in China [6]. The pathogen has since been identified as a novel enveloped positive-sense, single-stranded RNA betacoronavirus [7]. This virus, which has a phylogenetic similarity to SARS-CoV [8], has been given the name severe acute respiratory syndrome coronavirus 2 (SARS-CoV-2; also, COVID-19 virus). To date, among the total number of patients with COVID-19 globally, the case-fatality rate (ratio between the dead and total number of infected) ranges from 5.1 to $5.2 \%$ and is constantly increasing. This is ten times more than from the usual seasonal flu. Also, SARS-CoV-2 is supposed to be more contagious and environmentally stable than seasonal flu viruses, since seasonal flu usually ends by April in Northern hemisphere. In addition, it seems that the virus is also more likely to affect the heart than any other similar viruses, so although pneumonia is often the main cause of death, cardiologists and infectionists, for example in Russia, are seeing infected patients whose worst symptoms are not respiratory, but cardiac and many people infected with COVID-19 are dying from heart attacks, as a possible complication of SARS-CoV-2 infection. High expression of the ACE2 receptor, via which COVID-19 virus enters cells using its spike glycoprotein, was identified in type II alveolar cells (AT2) of the lung [9-11], esophagus upper and stratified epithelial cells, absorptive enterocytes from the ileum and colon [11], cholangiocytes [12], myocardial cells, kidney proximal tubule cells, and bladder urothelial cells. These findings indicate that those organs with high ACE2 expressing cells should be considered as a potential high risk for SARS-CoV-2 infection [9].
Investigations suggest that the spike glycoprotein of SARS-CoV-2 is the result of the combination of a bat SARS-CoV with an unknown Beta-CoV [13], probably a coronavirus of pangolin origin. The $\mathrm{S} 1$ subunit containing the receptor-binding domain region of the spike protein of Pangolin-CoV is much more closely related to that of SARS-CoV-2 than to that of the bat coronavirus RaTG13. Moreover, while five key amino acid residues involved in the interaction with human angiotensin-converting enzyme 2 (ACE2), mainly expressed in a small subset of cells in the lung called type 2 alveolar cells [8], are completely consistent between Pangolin CoV and SARS-CoV-2, four amino acid mutations are present in RaTG13 [2]. The spike protein of SARS-CoV-2 contains a 3-D structure in the receptorbinding domain region to maintain the van der Waals forces [14]. The 394 glutamine residue in the receptor-binding domain region of SARS-CoV-2 is recognized by the critical lysine 31 residue on the human angiotensin-converting enzyme 2 as a key receptor for virus penetration. It is also believed that the single N501T mutation in the SARS$\mathrm{CoV}-2$ spike protein (corresponding to the $\mathrm{S} 487 \mathrm{~T}$ mutation in SARS-CoV) may have significantly enhanced its binding affinity for human ACE2 and subsequent penetration [3].

For the human population, this is the third significant coronavirus infection to occur in the twenty-first century, following severe acute respiratory syndrome (SARS) in 2002-2003 and Middle East respiratory syndrome (MERS) in 2011. Both SARS-CoV and MERS-CoV were newly identified coronaviruses of zoonotic origin in the genus Betacoronavirus, with a much lower incidence than SARS-CoV-2: 8,096 cases for SARS since 2002 (mortality rate $\sim 10 \%$ ) and 2,494 cases for MERS since 2012 (mortality rate 35\%). Oddly enough, SARS-CoV-2 is not very similar to the genomes of SARS-CoV (about 79\%) or MERS-CoV (about $50 \%)[7,15]$. Despite the initial reports stating that most of the laboratory-confirmed infected patients (27 of 41 cases) had links to the Wuhan seafood market where different animals, including bats, snakes, birds, pangolins, and other small mammals are normally traded within the market [6], it is now obvious that the newly identified coronavirus SARS-CoV-2 is transmitted with enormous efficacy from human to human via respiratory droplets or close contact. The highly contagious nature of SARS-CoV-2 is probably due in large part to the virus spreading via asymptomatic infected individuals [16], which is exacerbated by an unusually long incubation period of up to 11-14 days. Based on data from hospitalized patients, the majority of COVID19 cases (about 80\%) presented as asymptomatic or with mild symptoms while the remainder were severe or critical $[6,17]$.

Most COVID-19 patients developed lymphopenia and pneumonia, with characteristic pulmonary ground-glass opacity changes seen on chest computed tomography $[6,17$, 
18]. SARS-CoV-2 is believed to dampen anti-viral interferon responses resulting in uncontrolled viral replication (for SARS-CoV and MERS-CoV, the response to viral infection by type I IFN is suppressed). The influx of neutrophils and monocytes/macrophages results in hyperproduction of pro-inflammatory cytokines [19]. The study of 41 hospitalized patients revealed high-levels of pro-inflammatory cytokines, including IL-2, IL-7, G-CSF, IP-10, MCP-1, MIP-1A, and TNF $\alpha$, in the most severe cases of COVID-19 [6]. This so-called 'cytokine storm' can initiate viral sepsis and inflammatory-induced lung injury, which lead to other complications including pneumonitis, acute respiratory distress syndrome (ARDS), respiratory failure, shock, organ failure, and potentially death [19]. Individuals particularly susceptible to COVID-19 are elderly people with underlying diseases, including diabetes, hypertension, and cardiovascular disease [6]. Since SARS-CoV-2 mutates constantly and more frequently than other RNA viruses (coronaviruses possess the longest genomes of all known RNA viruses, so more errors are made when they are copied; also viral RNAdependent RNA polymerases do not have a proofreading nuclease activity), it is likely that strains of the virus will appear whose host 'preference' will change, for instance, by reducing the average age of patients with a severe course of the disease. As global infection has progressed, we are now more frequently seeing young patients dying from COVID-19.

Tang et al. found single nucleotide polymorphisms (SNPs) in SARS-CoV-2 at location 8,782 (orf1ab polyprotein: T8517C, synonymous) and 28,144 (ORF8 protein: C251T, S84L, non-synonymous). Among the 103 SARS-CoV-2 virus strains in GenBank, 101 of them exhibited complete linkage between the two SNPs: 72 strains ( 71\%) exhibited a 'CT' haplotype (defined as L type because $\mathrm{T} 28144$ is in the codon of Leucine) and 29 strains ( 29\%) exhibited a 'TC' haplotype (defined as S type because C28144 is in the codon of Serine) at these two sites. Although the L type ( 71\%) was more prevalent than the S type ( 29\%) in the SARS-CoV-2 viruses examined, the $\mathrm{S}$ type is actually the ancestral version of SARS-CoV-2 (nucleotides of the $S$ type at sites 8782 and 28,144 were identical to the orthologous sites in the most closely related viruses). The ratio observed, 71:29, suggests that the L type has a higher transmission rate than the $\mathrm{S}$ type or was more prevalent at the start of the pandemic. Interestingly, while the L type was more prevalent in the early stages of the outbreak in Wuhan $(96.3 \% \mathrm{~L}: 3.7 \% \mathrm{~S})$, the frequency of the $\mathrm{L}$ type decreased after early January 2020 , possibly because human intervention efforts may have caused severe selective pressure against the L type [20].

What about reinfection? Earlier, a pivotal role for virusspecific memory T-cells in broad and long-term protection against SARS-CoV infection was elucidated [21,
22]. Indeed, the crucial protective role of T-cell immune responses in coronavirus infections has been clearly documented in several animal models, e.g., feline infectious peritonitis virus (FIPV), mouse hepatitis virus (MHV), and avian infectious bronchitis virus (IBV) [23-25]. Moreover, reinfection did not occur in SARS-CoV-2 infected rhesus macaques with the same strain [26]. What about reinfection with other possible strains of people who recovered from initial infection with one strain? At present, it remains unclear whether convalescing patients are at risk for relapse or reinfection. It is also worth noting the theory that coronavirus infections might play a part in multiple sclerosis. It is known that mouse hepatitis virus, a murine coronavirus, is a close relative of common human coronavirus HCoV-OC43, which causes a multiple sclerosis-like demyelinating disease in the central nervous system of rodents [27]. Some studies have suggested that human coronaviruses, in particular $\mathrm{HCoV-OC43,} \mathrm{may} \mathrm{be} \mathrm{involved} \mathrm{in} \mathrm{gastrointestinal} \mathrm{disease.}$ Coronaviruses can be detected in stool samples, and antibodies directed to $\mathrm{HCoV}-\mathrm{OC} 43$ have been observed more frequently in children with gastroenteritis [28]. Thus, the future health of people who have recovered from COVID-19 may be accompanied by complications.

It should be noted that in nature the number of host organisms is regulated by parasites, including viruses. Outbreaks are eventually replaced by a population decline (Lotka-Volterra system of equations, as an example of a Kolmogorov model). It is necessary to consider the r-strategy of virus survival in which a large number of descendants as well as mutants are formed. Based on the Lotka-Volterra equations, when the human population declines as the result of the action of a virus, following a delay, the overall population of the virus also decreases. Thus, in the human population, during the decline phase, the majority of individuals have genotypes adapted for the virus strains prevailing at the moment. Under these circumstances, the human population will start to grow until the virus genotypes capable of suppressing the human population significantly appear again. The same line of reasoning can be applied to a 'medical drug-virus' system, except that a drug cannot change by itself. Therefore, it is necessary to control viruses constantly with new drugs developed for use against both new strains of viruses and new species of viruses to save the lives of virus-sensitive people. Taking into consideration the natural genetic mechanisms of mutations and recombination, it is impossible to imagine how to deprive a virus of the opportunity to generate new strains and time to time threaten our world with new pandemics.

It must be understood that the short-term relationship between the virus and the host is always the result of Darwin's microevolution. Individuals who do not die in the fight against the virus will form a generation that is more resistant to the virus over time. The virus will continue to 
reproduce in these individuals, but will not pose a great danger to them. On the other hand, humanity is capable of inventing drugs against viruses and slowing down the progress of Darwin's microevolution, saving the lives of those who otherwise might die without treatment. Would COVID-19 patients after successful treatment or recovery again become severely infected with other strains of this virus? There are no guarantees at the moment, but it is clear that the virus will continue to circulate and kill the people who are most susceptible to it.

Thus, based on the facts accumulated so far, it is clear that while the new coronavirus is more aggressive, it does not have mortality rates as high as those seen with SARSCoV and MERS-CoV. Humanity will definitely survive. Drugs and vaccines will save the lives of some virussensitive people. Deaths among people of reproductive age will gradually lead to a human population in which the next generations will be more resistant to this virus (Fig. 1). This is one of the primary reasons why pandemics of Spanish flu (H1N1 subtype) did not last for many years because the overwhelming majority of people who died were aged 18-45. Individuals genetically resistant to the virus survived it and formed the next virus-resistant generation. Published studies indicate that $20-40 \%$ of populations in some areas have been infected by the H1N1 virus and thus have some level of protective immunity [29].
The origin of SARS-CoV-2 is not completely understood. If this virus is man-made, then it is necessary to go back 45 years and rethink the results of the Asilomar conference on recombinant DNA held in 1975, when scientists met to discuss the potential biohazards and regulation of biotechnology and banned some potentially dangerous experiments, including cloning of recombinant DNAs derived from highly pathogenic organisms. If the virus is of natural origin, then it is necessary to understand how new coronaviruses are transferred from animal reservoirs to humans and reduce the likelihood of a person coming into contact with them. In addition, it is imperative to develop new vaccines and drugs against coronavirus infection in case of emergency.

Is it important today to stop the spread of infection as quickly as possible? Yes, if possible, it must be stopped. However, is it in our power to do so when the official number of diagnosed cases has already exceeded 1 million people worldwide? Probably not. In some cases, the human population has been able to completely obliterate a viral disease by enacting successful anti-epidemiological measures, as happened with the smallpox virus [30], but smallpox virus had no animal reservoir. Apparently, COVID-19 is not one of these cases. In our opinion, the high contagiousness of SARS-CoV-2 and the ability of coronaviruses to persist for a long time in host organisms [31, 32] will allow the COVID19 virus to continue to circulate in the human population until the fall of 2020 when a new pandemic wave seems
Fig.1 The relationship between SARS-CoV-2 and the human population (increasing numbers of SARS-CoV-2-resistant individuals over time)

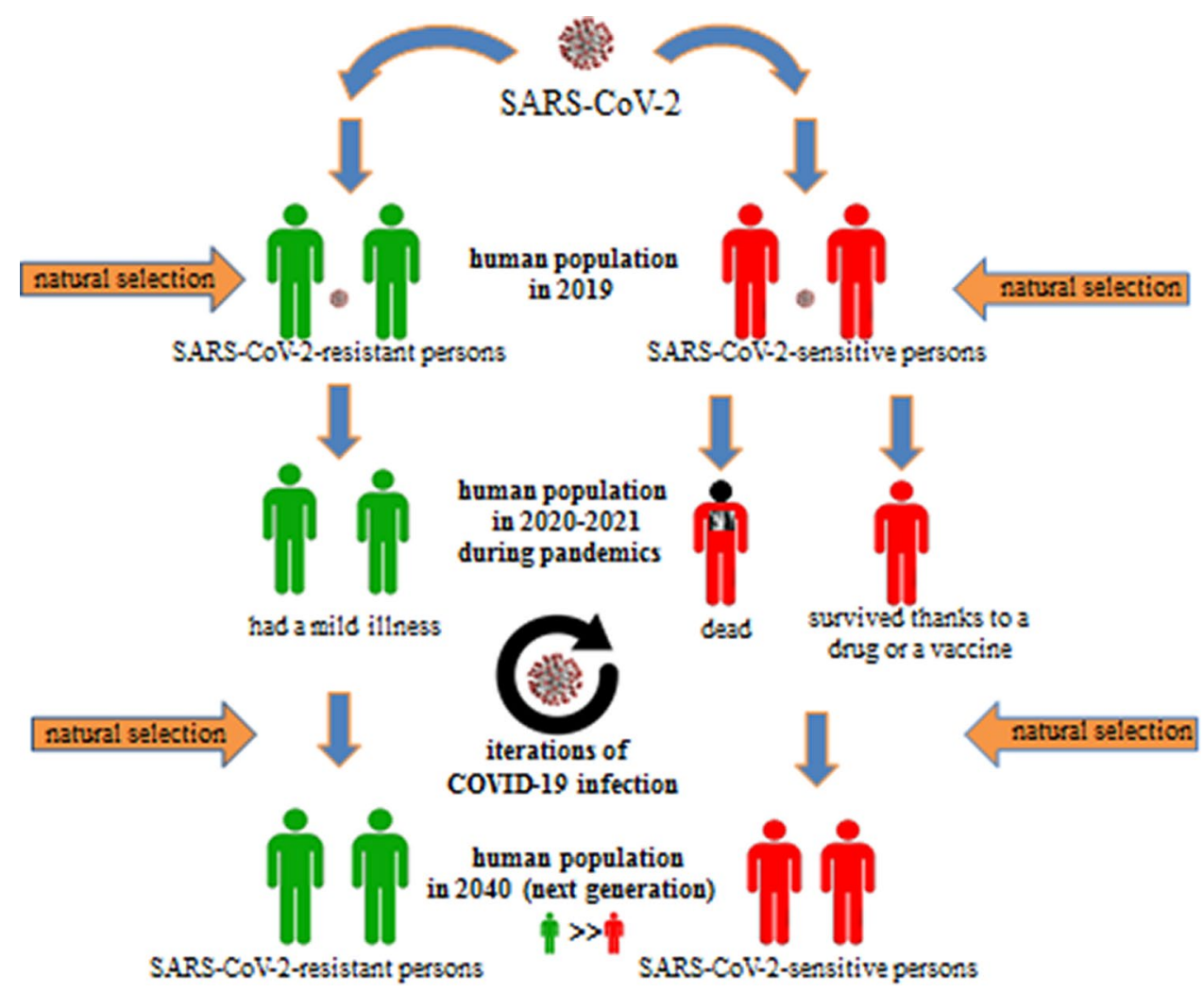


to occur again. The most likely outcome is that this new coronavirus (as occurred with the four other well-known non-severe acute respiratory syndrome (nonSARS)-related human coronaviruses (HCoVs), including $\mathrm{HCoV}-229 \mathrm{E}$, -OC43, -HKU1, and -NL63) will take its place next to the seasonal flu viruses, where the infection rate is high and the mortality rate is very low. In the near future, your doctor will routinely prescribe you something like 'covidol' and say that in the coming days you are likely to recover. Interestingly, after the discovery of non-SARS HCoV-NL63 and HCoVHKU1, several groups reported infections by these viruses in different countries, illustrating that these viruses have spread worldwide [33-39]. The viruses can be detected in $1-10 \%$ of patients with acute respiratory tract infections, and double infections with other respiratory viruses are common [37]. Of note, for SARS-CoV, a close relative of SARS-CoV-2, there is evidence of at least seven potential regions of recombination in the SARS-CoV genome in the replicase- and Spike-coding regions, with possible recombination partners that include porcine epidemic diarrhea virus (PEDV), transmissible gastroenteritis virus (TGEV), bovine coronavirus (BCoV), HCoV-229E, MHV, and IBV [40]. A similar study involving the human coronavirus HCoV-NL63 likewise demonstrated that HCoV-NL63 exhibited signs of having arisen from multiple recombination events from its nearest relative over the course of hundreds of years [41]. Thus, it is possible that SARS-CoV-2, through multiple recombination events, can trigger an outbreak of respiratory diseases caused by new strains of nonSARS-related human HCoVs.

Now, as a century ago during the Spanish flu pandemic, the emphasis on washing hands frequently, avoiding crowds, and wearing masks are recurrent in newspaper records and on websites, as is disdain for people flouting the rules. In the meantime, when we wash our hands with soap, we should thank providence that the SARS-CoV-2 does not have the same mortality rate as MERS-CoV. As the situation stands right now, it is better to become infected with COVID-19 as late as possible to allow vaccines and drugs to be developed and tested, as there are no guarantees yet concerning who is at risk of a severe course of the disease and who is not. Apparently, the bitter and unpopular truth is that most of the world's inhabitants need to make contact with the SARS-CoV-2 before we can all return to normal life. Quarantine slows down this process, gaining time for doctors and scientists who, through their professional activities, can save virus-sensitive individuals. So often, we have to choose: quickly but painfully, or gently but slowly. Today we find ourselves in a zugzwang situation: a greater number of deaths, or the collapse of the global economy. We are on the second path so far, but soon we will need to reach a compromise because SARS-CoV-2 will continue to circulate in the human population. This coronavirus is with us forever. Perhaps we can learn from the seasonal flu viruses that kill hundreds of thousands of people every year; since we are used to these viruses, they do not scare us anymore, so we have reached the compromise that lets us all move forward.

\section{References}

1. Andersen KG, Rambaut A, Lipkin WI, et al. The proximal origin of SARS-CoV-2. Nat Med. 2020;26:450-2. https://doi. org/10.1038/s41591-020-0820-9.

2. Zhang TWQ, Zhang Z. Probable pangolin origin of SARSCoV-2 associated with the COVID-19 outbreak. Curr Biol. 2020;20:30360-2. https://doi.org/10.1016/j.cub.2020.03.022.

3. Wan Y, Shang J, Graham R, Baric RS, Li F. Receptor recognition by novel coronavirus from Wuhan: An analysis based on decadelong structural studies of SARS. J Virol. 2020;94(7):1-13. https ://doi.org/10.1128/JVI.00127-20.

4. Sheahan T, et al. Mechanism of zoonotic severe acute respiratory syndrome coronavirus host range expansion in human airway epithelium. J Virol. 2008;82:2274-85. https://doi.org/10.1128/ JVI.02041-07.

5. Liu S, Saif L, Weiss S, Su L. No credible evidence supporting claims of the laboratory engineering of SARS-CoV-2. Emerg Microbes Infect. 2020;9(1):505-7. https://doi.org/10.1080/22221 751.2020 .1733440 .

6. Huang C, Wang Y, Li X, et al. Clinical features of patients infected with 2019 novel coronavirus in Wuhan. China Lancet. 2020;395:497-506. https://doi.org/10.1016/S0140-6736(20)30183 -5 .

7. Lu R, Zhao X, Li J, et al. Genomic characterisation and epidemiology of 2019 novel coronavirus: implications for virus origins and receptor binding. Lancet. 2020;395:565-74. https://doi. org/10.1016/S0140-6736(20)30251-8.

8. Zhu N, Zhang D, Wang W, et al. A novel coronavirus from patients with pneumonia in China, 2019. N Engl J Med. 2020;382:727-33. https://doi.org/10.1056/NEJMoa2001017.

9. Zou X, et al. The single-cell RNA-seq data analysis on the receptor ACE2 expression reveals the potential risk of different human organs vulnerable to Wuhan 2019-nCoV infection. Front Med. 2020. https://doi.org/10.1007/s11684-020-0754-0.

10. Zhao Y, et al. Single-cell RNA expression profiling of ACE2, the putative receptor of Wuhan 2019-nCov. bioRxiv [Preprint]. 2020. https://doi.org/10.1101/2020.01.26.919985.

11. Zhang $\mathrm{H}$, et al. The digestive system is a potential route of 2019-nCov infection: a bioinformatics analysis based on single-cell transcriptomes. bioRxiv [Preprint]. 2020. https://doi. org/10.1101/2020.01.30.927806.

12. Chai $X$, et al. Specific ACE2 expression in cholangiocytes may cause liver damage after 2019-nCoV infection. bioRxiv [Preprint]. 2020. https://doi.org/10.1101/2020.02.03.931766.

13. Li CB, Si H-R, Zhu Y, Yang X-L, Anderson DE, Shi Z-L, et al. Discovery of bat coronaviruses through surveillance and probe capture-based next-generation sequencing. Msphere. 2020. https ://doi.org/10.1128/mSphere.00807-19.

14. Xu X, Chen P, Wang J, Feng J, Zhou H, Li X, et al. Evolution of the novel coronavirus from the ongoing Wuhan outbreak and modeling of its spike protein for risk of human transmission. Sci China Life Sci. 2020;63(3):457-60. https://doi.org/10.1007/s1142 7-020-1637-5.

15. Gralinski LE, Menachery VD. Return of the coronavirus: 2019nCoV. Viruses. 2020. https://doi.org/10.3390/v12020135.

16. Rothe C, Schunk M, Sothmann P, Bretzel G, Froeschl G, Wallrauch $\mathrm{C}$, et al. Transmission of 2019-nCoV infection from an 
asymptomatic contact in Germany. N Engl J Med [Preprint]. 2020;26(6):2. https://doi.org/10.1056/NEJMc2001468.

17. Chan JF, Yuan S, Kok KH, To KK, Chu H, Yang J, et al. A familial cluster of pneumonia associated with the 2019 novel coronavirus indicating person-to-person transmission: a study of a family cluster. Lancet. 2020;395:514-23. https://doi.org/10.1016/s0140 -6736(20)30154-9.

18. Wu F, Zhao S, Yu B, Chen YM, Wang W, Song ZG, et al. A new coronavirus associated with human respiratory disease in China. Nature [Preprint]. 2020;579(7798):19. https://doi.org/10.1038/ s41586-020-2008-3.

19. Prompetchara E, Ketloy C, Palaga T. Immune responses in COVID-19 and potential vaccines: Lessons learned from SARS and MERS epidemic. Asian Pac J Allergy Immunol. 2020;38(1):1-9. https://doi.org/10.12932/ap-200220-0772.

20. Tang X, Wu C, Li X, Song Y, Yao X, Wu X, et al. On the origin and continuing evolution of SARS-CoV-2. Natl Sci Rev. 2020. https://doi.org/10.1186/s40779-020-00240-0.

21. Zhao CJ, Zhao J, Perlman S. T cell responses are required for protection from clinical disease and for virus clearance in severe acute respiratory syndrome coronavirus-infected mice. J Virol. 2010. https://doi.org/10.1128/JVI.01049-10.

22. Channappanavar R, Fett C, Zhao J, Meyerholz DK, Perlman S. Virus-specific memory CD8 $\mathrm{T}$ cells provide substantial protection from lethal severe acute respiratory syndrome coronavirus infection. J Virol. 2014;88:11034-44. https://doi.org/10.1128/ JVI.01505-14.

23. Li H, Wang Y, Han Z, Wang Y, Liang S, Jiang L, Hu Y, Kong $X$, Liu S. Recombinant duck enteritis viruses expressing major structural proteins of the infectious bronchitis virus provide protection against infectious bronchitis in chickens. Antivir Res. 2016;130:19-26. https://doi.org/10.1016/j.antiviral.2016.03.003.

24. Takano CT, Tomizawa K, Morioka H, Doki T, Hohdatsu T. Evaluation of protective efficacy of the synthetic peptide vaccine containing the T-helper 1 epitope with $\mathrm{CpG}$ oligodeoxynucleotide against feline infectious peritonitis virus infection in cats. Antivir. Ther. 2014. https://doi.org/10.3851/IMP2735.

25. Trujillo JA, Gras S, Twist KA, Croft NP, Channappanavar R, Rossjohn J, Purcell AW, Perlman S. Structural and functional correlates of enhanced antiviral immunity generated by heteroclitic CD8 T cell epitopes. J Immunol. 2014;192:5245-56. https://doi. org/10.4049/jimmunol.1400111.

26. Bao L, Deng W, Gao H, Xiao C, Liu J, Xue J, et al. Reinfection could not occur in SARS-CoV-2 infected rhesus macaques. bioRxiv [Preprint]. 2020. https://doi. org/10.1101/2020.03.13.990226.

27. Fazakerley JK, Buchmeier MJ. Pathogenesis of virus-induced demyelination. Adv Virus Res. 1993. https://doi.org/10.10116/ S0065-3527(08)60087-1.

28. Gerna G, Passarani N, Battaglia M, Revello MG, Torre D, Cereda PM. And gastroenteritis: evidence of antigenic relatedness between human enteric coronavirus strains and human coronavirus OC43. Microbiologica. 1984;7:315-22. https://doi. org/10.1016/j.jcv.2010.03.007.
29. Recent news from WHO. Bull World Health Organ. 2010; 1;88(10). https://doi.org/10.2471/BLT.10.041010

30. Strassburg MA. The global eradication of smallpox. Am J Infect Control. 1982;10:53-9. https://doi.org/10.1016/01966553(82)90003-7.

31. Graham RL, Baric RS. Recombination, reservoirs, and the modular spike: mechanisms of coronavirus cross-species transmission. J Virol. 2010;84:3134-46. https://doi.org/10.1128/JVI.01394-09.

32. De Wilde AH, Snijder EJ, Kikkert M, van Hemert MJ. Host factors in coronavirus replication. Curr Top Microbiol Immunol. 2018;419:1-42. https://doi.org/10.1007/82_2017_25.

33. Arden KE, Nissen MD, Sloots TP, Mackay IM. New human coronavirus, HCoV-NL63, associated with severe lower respiratory tract disease in Australia. J Med Virol. 2005;75:455-62. https:// doi.org/10.1002/jmv.20288.

34. Bastien N, Anderson K, Hart L, Van Caeseele P, Brandt K, Milley D, Hatchette T, Weiss EC, Li Y. Human coronavirus NL63 infection in Canada. J Infect Dis. 2005;191:503-6. https://doi. org/10.1086/426869.

35. Chiu SS, Chan KH, Chu KW, Kwan SW, Guan Y, Poon LL, Peiris JS. Human coronavirus NL63 infection and other coronavirus infections in children hospitalized with acute respiratory disease in Hong Kong. China Clin Infect Dis. 2005;40:1721-9. https:// doi.org/10.1086/430301.

36. Choi EH, Lee HJ, Kim SJ, Eun BW, Kim NH, Lee JA, Lee JH, Song EK, Kim SH, Park JY, Sung JY. The association of newly identified respiratory viruses with lower respiratory tract infections in Korean children, 2000-2005. Clin Infect Dis. 2006;43:585-92. https://doi.org/10.1086/506350.

37. Ebihara T, Endo R, Ma X, Ishiguro N, Kikuta H. Detection of human coronavirus NL63 in young children with bronchiolitis. J Med Virol. 2005;75:463-5. https://doi.org/10.1002/jmv.20289.

38. Esper F, Weibel C, Ferguson D, Landry ML, Kahn JS. Coronavirus HKU1 infection in the United States. Emerg Infect Dis. 2006;12:775-9. https://doi.org/10.3201/eid1205.051316.

39. van der Hoek L, Pyrc LK, Berkhout B. Human coronavirus NL63, a new respiratory virus. FEMS Microbiol Rev. 2006;30:760-73. https://doi.org/10.1111/j.1574-6976.2006.00032.x.

40. Zhang XW, Yap YL, Danchin A. Testing the hypothesis of a recombinant origin of the SARS-associated coronavirus. Arch Virol. 2005;150:1-20. https://doi.org/10.1007/s0070 5-004-0413-9.

41. Pyrc K, Dijkman R, Deng L, Jebbink MF, Ross HA, Berkhout B, van der Hoek L. Mosaic structure of human coronavirus NL63, one thousand years of evolution. J Mol Biol. 2006;364:964-73. https://doi.org/10.1016/j.jmb.2006.09.074.

Publisher's Note Springer Nature remains neutral with regard to jurisdictional claims in published maps and institutional affiliations. 